DOI: $10.5216 /$ cab.v13i4.17429

\title{
OCORRÊNCIA DE LENTIVÍRUS DE PEQUENOS RUMINANTES NO SEMIÁRIDO BAIANO E PERFIL DA CAPRINO/OVINOCULTURA NA REGIÃO
}

\author{
Silvia Ines SARdi ${ }^{1}$, Glauber SANTos Ribeiro de Sena ${ }^{2}$, Gubio SoARes CAMpos ${ }^{1}$, Gisele Rocha \\ SANTOS $^{3}$, ANTÔNIO LEMOS MAIA NETO ${ }^{4}$, LUCIANA NIEDERSBERG DE AVILA ${ }^{4}$ \\ ${ }^{1}$ Professores Doutores da Universidade Federal da Bahia, Salvador, BA, Brasil. sissardi@ yahoo.com.br \\ ${ }^{2}$ Pós graduando da Universidade Federal da Bahia, Salvador, BA, Brasil. \\ ${ }^{3}$ Médica Veterinária graduada pela Universidade Federal da Bahia, Salvador, BA, Brasil. \\ ${ }^{4}$ Técnicos da Agência Estadual de Defesa Agropecuária da Bahia, Diretoria de Defesa Sanitária Animal, Salvador, BA, Brasil.
}

\begin{abstract}
Este trabalho teve como objetivo avaliar, no território do semiárido baiano, a presença do Lentivirus de pequenos ruminantes (SRLV: Artrite encefalite caprina, CAEV, e Maedi-Visna, MVV) e caracterizar o perfil socioeconômico da caprino/ovinocultura nessa região. Em 134 propriedades do Portal do Sertão, Sisal e Bacia do Jacuípe foram coletadas amostras de soros de caprinos $(n=1046)$ e ovinos $(n=704)$, para detecção de anticorpos para CAEV e MVV pelo teste de Imunodifusão (IDGA) e ELISA e Western Blot para CAEV. Durante a visita em cada fazenda, aplicou-se um questionário para definir o perfil socioeconômico da caprino/ovinocultura da propriedade. Os resultados mostraram a ausência de

soropositivos para MVV e CAEV pelo IDGA, mas 5/755 caprinos foram positivos para CAEV pelo ELISA e confirmados no Western blot. O questionário aplicado mostrou um perfil produtivo pouco tecnificado, com predomínio de propriedades de gestão familiar, sem investimentos tecnológicos, rebanhos de ovinos e caprinos sem raça definida, criados em sistema extensivo e destinados principalmente à subsistência familiar. Concluindo, este trabalho mostra que a região do semiárido baiano tem uma baixa ocorrência do SRLV, e o desenvolvimento da caprino/ovinocultura é voltado à criação de animais para consumo familiar ou obtenção de renda nos mercados locais.
\end{abstract}

PALAVRAS-CHAVE: diagnóstico; Lentivirus de pequenos ruminantes; produtividade; semiárido.

\section{OCCURRENCE OF SMALL RUMINANT LENTIVIRUS IN THE SEMI-ARID OF BAHIA AND THE PRODUCTIVITY PROFILE OF THE REGION}

\section{ABSTRACT}

The aim of this study was to analyze the occurrence of Small Ruminants Lentiviruses (SRLV: Caprine arthrite encephalitis virus, CAEV, and Maedi-Visna, MVV) and characterize the social/economical profile of the farms in the semi-arid region of Portal do Sertão, Sisal e Bacia do Jacuípe, in the state of Bahia, Brazil. Sera from goats $(\mathrm{n}=$ 1046) and sheep (704) were collected to detect antibodies against CAEV and MVV by Agar Immunodifusion (AGID) and ELISA and Western Blot for CAEV. A questionnaire was applied to each farm where sera were collected in order to define the social/economical profile. The results obtained by AGID showed no positive goats and sheep for infection by CAEV or MVV, respectively, but $5 / 755$ sera were positive for CAEV by ELISA and 
confirmed by Western blot. The questionnaire analysis showed a low technical profile in the smallholders, under familiar management, whose flocks were raised in an extensive system destined to self-consumption or local trading. In conclusion, this work demonstrated a low incidence of SRLV, and that the production in the farms of the semi-arid region is based mainly in goat and sheep herds without specific breed, destined for for selfconsumption or local commercialization.

KEYWORDS: diagnosis; productivity; semi-arid; Small Ruminant Lentivirus.

\section{INTRODUÇÃO}

A caprino/ovinocultura é uma importante atividade socioeconômica no semiárido brasileiro. A viabilidade dessa atividade deve-se à resistência dos animais às condições ambientais da região, caracterizada pelo clima quente e seco (precipitação anual inferior a $800 \mathrm{~mm} / \mathrm{ano}$ ), com longos períodos de estiagem.

Apesar de a caprino/ovinocultura estar amplamente difundida e adaptada no semiárido, os produtores têm encontrado dificuldade em formar excedentes comerciáveis que favoreçam ao acúmulo de capital, sendo que essa produção às vezes não atende sequer ao próprio sustento (LIMA \& BAIARDI, 2000). Os fatores nutricionais, sanitários ou falta de organização na produção podem ser os principais limitantes que dificultam a intensificação dessa exploração na região (LEITE \& SIMPLÍCIO, 2002).

Dentre os aspectos sanitários importantes para a caprino/ovinocultura está o controle e a prevenção do Lentivirus de pequenos ruminantes (SRLV), vírus da família Retroviridae, formado por dois vírus estreitamente relacionados: o vírus da Artrite Encefalite Caprina (CAEV) e o Maedi-Visna (MVV) (GOFF, 2006). Esses vírus infectam células da linhagem monócitos/macrófagos (TIGRE et al., 2006) e levam a manifestações clínicas de artrite, mamite ou encefalite em animais jovens (FRANKE, 1998) no caso de CAEV, enquanto a infecção pelo MVV tem como principal manifestação a pneumonia crônica (MCNEILLY et al., 2008). Entretanto, quando ocorrem manifestações clínicas, esses sinais se manifestam normalmente em estágios avançados da doença, facilitando a existência de portadores sadios que favorecem a disseminação do vírus no rebanho.

$\mathrm{Na}$ Bahia, estado com o maior rebanho de caprinos do país, com mais de 2,1 milhões de animais, e o segundo maior rebanho de ovinos, com aproximadamente 2,6 milhões de animais (IBGE, 2005), a caprino/ovinocultura merece especial atenção pela importância socioeconômica, principalmente na região semiárida. Poucos são os dados que reportam o perfil da produção de caprinos e ovinos na região baiana (SOUZA et al., 2007; PAMPONET, 2009). As atividades nessa região carecem, frequentemente, de ações de capacitação, extensão e educação em saúde animal para limitar fatores causadores de baixos índices produtivos, principalmente fatores sanitários, como as doenças progressivas crônicas, que constituem um desafio para o produtor de caprinos e ovinos, pois um diagnóstico precoce, eficiente e de baixo custo nem sempre está ao seu alcance. Os estudos realizados na Bahia mostram uma prevalência de 13-20\% de SLVR em rebanhos de cabras leiteiras; entretanto, o diagnóstico laboratorial ainda é escasso (TIGRE et al., 2006, TORRES et.al., 2009)

Para detecção da infecção pelo vírus, utilizase a Imunodifusão em Ágar Gel (IDGA), recomendado pela OIE (Organização Internacional de Epizootias) como teste de referência para detecção de anticorpos contra CAEV e MVV. No entanto, por ser um teste pouco sensível, pode levar a resultados falso-negativos (TORRES et al., 2009). Por isso, em paralelo ao uso do IDGA, podem ser utilizados testes mais sensíveis para detecção de anticorpos como testes de ELISA e o Western Blot. Essas técnicas são utilizadas em países europeus que possuem programas de erradicação ou de controle da infecção com o estabelecimento de propriedades livres de SRLV (SYNGE \& RITCHIE, 2010)

Este trabalho teve como objetivo avaliar a infecção pelo SRLV em rebanhos caprinos e ovinos em territórios de identidade do semiárido baiano (Portal do Sertão, Sisal e Bacia do Jacuípe), assim como analisar as características do perfil produtivo da caprino/ovinocultura na região estudada.

\section{MATERIAL E MÉTODOS}

O estudo foi realizado em propriedades de municípios de territórios de identidade do semiárido baiano (SEAGRI, 2012): Portal do Sertão, Bacia do Jacuípe e Sisal (Figura 1). 


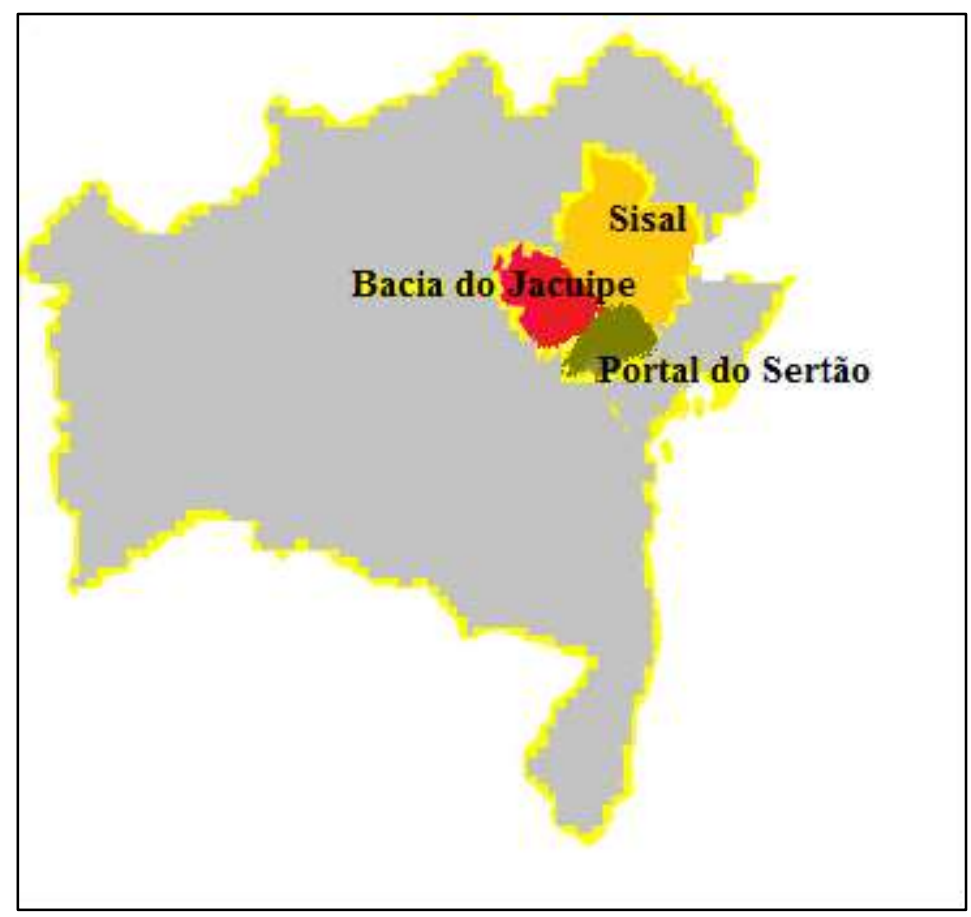

Figura 1. Territórios de identidade do semiárido baiano (Fonte: SEAGRI, 2012)

Foram escolhidas aleatoriamente 134 propriedades, segundo o cadastro do Programa Nacional de Febre Aftosa para a Bahia, e delas foram coletadas amostras de sangue de 1046 caprinos e 704 ovinos jovens, de 1 a 4 anos, de ambos os sexos e aparentemente sadios. A amostragem representava um mínimo de $10 \%$ do total de animais cada rebanho. Das amostras de sangue dos caprinos e ovinos, os soros foram coletados e submetidos ao teste IDGA para detecção de anticorpos para CAEV (Antígeno CAEV - IDGA; Biovetech®, Brasil) e MVV (Antígeno Maedi-Visna - IDGA; Biovetech®, Brasil), seguindo as indicações do fabricante. Dos 1074 soros caprinos, foram escolhidos aleatoriamente 755 soros para ser avaliados pela técnica de ELISA indireto, desenvolvida no laboratório de virologia do ICS-UFBA (TORRES et al., 2009).

Os soros de caprinos positivos para ELISA $(\mathrm{n}=5)$ foram submetidos à técnica de Western-blot. Brevemente, a corrida eletroforética de proteínas do antígeno viral obtido de cultura de membrana sinovial infectada (TORRES et al., 2009) e do antígeno celular obtido de cultura de membrana sinovial sem infectar (controle negativo) realizou-se em gel de poliacrilamida (SDS-PAGE) $10 \%$ e, logo depois, as proteínas foram eletrotransferidas a uma membrana de nitrocelulose (AMERSHAM

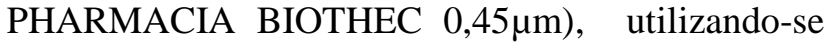
uma cuba de transferência com buffer Glicina 192 $\mathrm{mM}$, Tris $25 \mathrm{mM}$ e Metanol 20\%, a 100 volts durante 1 hora. Uma vez realizada a transferência, a membrana de nitrocelulose foi cortada em fitas, bloqueadas com uma solução de leite em pó desnatado 5\% em PBS e incubadas, individualmente, com os diferentes soros (1:50 em PBS-Leite 0,5\%), ou anticorpo monoclonal para CAEV (1:10 em PBSLeite $0,5 \%$ ), durante toda a noite, à temperatura ambiente. Logo depois, foram submetidas a três lavagens com PBS-Tween $200,05 \%$ e novamente incubadas durante 1 hora a $37^{\circ} \mathrm{C}$, com um anticorpo anti-IgG de cabra (1:500) ou anticorpo anti-IgG de camundongo (1:1000), conjugado à peroxidase (SIGMA Co, USA). A revelação foi feita com uma solução com 3'3' Diaminobenzidine (DAB) $(10 \mathrm{mg} / 10 \mathrm{ml})$ na presença de peróxido de hidrogênio $(0,001 \%)$.

O perfil socioeconômico da caprino/ovinocultura foi investigado durante as visitas às fazendas, e os proprietários foram convidados a responder um questionário acerca do tipo de exploração, característica do rebanho, aspectos do manejo alimentar e sanitário, tecnificação, destino da produção, dentre outras questões (Tabelas 2-4). Os resultados dos questionários foram analisados por meio de 
Estatística Descritiva utilizando-se o programa Statistics Packing Social Science (SPSS) para Windows 14.0.

\section{RESULTADOS E DISCUSSÃO}

O uso do teste de referência IDGA para detecção de anticorpos para CAEV ou MVV mostrou que a totalidade dos caprinos $(n=1046)$ e ovinos $(n=704)$ analisados não tinham anticorpos para os dois vírus. Esses resultados foram similares a outros levantamentos sorológicos realizados em outras regiões do semiárido baiano utilizando-se IDGA (ALMEIDA et al., 2001; SOUZA et al., 2007). Entretanto, $5 / 755$ soros caprinos testados pela técnica de ELISA indireta apresentaram resultado positivo (Tabela 1).

Tabela 1. Territórios de identidade, municípios e propriedades avaliadas.

\begin{tabular}{lccc}
\hline Territórios de Identidade & Municípios & $\begin{array}{c}\text { Número de } \\
\text { Propriedades }(\%)\end{array}$ & $\begin{array}{c}\text { Animais CAEV positivos/ } \\
\text { Municípios }\end{array}$ \\
\hline Bacia do Jacuípe & 13 & $29(21,6 \%)$ & $3 / 13$ \\
Portal do Sertão & 7 & $25(18,7 \%)$ & $0 / 7$ \\
Sisal & 16 & $80(59,7 \%)$ & $2 / 16$ \\
Total & 36 & $134(100 \%)$ & $5 / 36$ \\
\hline
\end{tabular}

A detecção de soropositivos por meio do ELISA pode ser compreendida pela maior sensibilidade do teste para detectar precocemente a infecção como descrito por TORRES et al. (2009). A confirmação da reatividade dos soros positivos para ELISA foi demonstrada no Western-blot (Figura 2), em que se observa a reação dos soros contra a proteína viral de $28 \mathrm{kDa}$, correspondente à proteína mais imunogênica do vírus CAEV (OLIVEIRA et al., 2008). Observou-se também reação contra proteínas de peso molecular maior, a proteína viral de $36 \mathrm{kDa}$ (produto intermediário de $\mathrm{p} 55^{\mathrm{gag}}$ ), mas como aparentemente também foram observadas no controle celular não infectado, isso pode ser interpretado como uma reação cruzada com proteínas de origem celular. A proteína viral $\mathrm{p} 55^{\mathrm{gag}}$ é um precursor poliproteico que sofre uma clivagem que origina subprodutos como as proteínas da cápside (CA p28), da matriz (MA p19) e do nucleocapsídeo (NC p16) (GOFF, 2006).

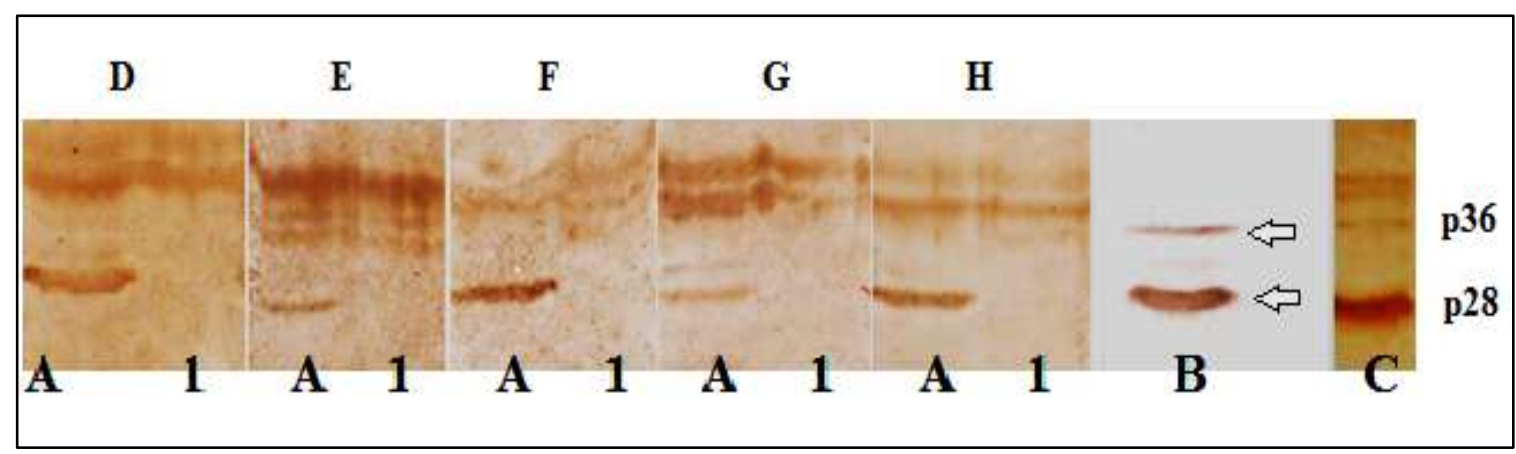

Figura 2. Análise por Western blot dos soros CAEV positivos.

D-H: Perfil de reação dos cinco soros caprinos ELISA positivos; A: Antígenos virais,

1: Antígenos celulares (controle negativo); B: Antígenos virais frente a anticorpo monoclonal para CAEV;

C: Antígenos virais frente a soro de referência caprino positivo para CAEV.

O questionário aplicado foi relevante para determinar as características da caprino/ovinocultura nas propriedades estudadas. A Tabela 2 apresenta algumas dessas características. Nela observamos que a caprino/ovinocultura da região é predominantemente de tipo familiar em $64,7 \%$, com uma criação tipo extensiva em 59,8\% dos casos. Os resultados revelaram um baixo nível de tecnificação, 
com assistência técnica em apenas $38,6 \%$ das propriedades e com uma fraca introdução de inovações tecnológicas, visto que em somente $7,8 \%$ das propriedades houve investimento em equipamentos e máquinas nos últimos dois anos anteriores à pesquisa.

Tabela 2. Características das propriedades analisadas

\begin{tabular}{|c|c|c|c|}
\hline Variável & Número de Fazendas & Porcentagem & Validação $^{1}(\%)$ \\
\hline \multicolumn{4}{|l|}{ Tipo de Gestão } \\
\hline Contratada & 41 & 30,6 & 35,3 \\
\hline Familiar & 75 & 56,0 & 64,7 \\
\hline Sem dados ${ }^{2}$ & 18 & 13,4 & ---- \\
\hline Total & 134 & 100,0 & 100,0 \\
\hline \multicolumn{4}{|c|}{ Sistema de Criação } \\
\hline Extensivo & 79 & 59,0 & 59,8 \\
\hline Intensivo & 8 & 6,0 & 6,1 \\
\hline Semi-Intensivo & 45 & 33,6 & 34,1 \\
\hline Sem Dados & 2 & 1,5 & --- \\
\hline Total & 134 & 100,0 & 100,0 \\
\hline \multicolumn{4}{|c|}{ Investimento máquinas/equipam/ últimos 2 anos } \\
\hline Não & 95 & 70,9 & 92,2 \\
\hline Sim & 8 & 6,0 & 7,8 \\
\hline Sem Dados & 31 & 23,1 & ---- \\
\hline Total & 134 & 100,0 & 100,0 \\
\hline \multicolumn{4}{|c|}{ Assistência sanitária/sanidade } \\
\hline Proprietário & 62 & 46,3 & 61,4 \\
\hline Técnico & 39 & 29,1 & 38,6 \\
\hline Sem Dados & 33 & 24,6 & ---- \\
\hline Total & 134 & 100,0 & 100,0 \\
\hline \multicolumn{4}{|c|}{ Pastagem/Pastoreio } \\
\hline Terra própria & 110 & 82,1 & 99,1 \\
\hline Terra coletiva & 1 & 0,7 & 0,9 \\
\hline Sem Dados & 23 & 17,2 & ---- \\
\hline Total & 134 & 100,0 & 100,0 \\
\hline \multicolumn{4}{|c|}{ Suplemento Alimentar } \\
\hline Não & 12 & 9,0 & 11,5 \\
\hline $\operatorname{Sim}$ & 92 & 68,7 & 88,5 \\
\hline Sem dados & 30 & 22,4 & ---- \\
\hline Total & 134 & 100,0 & 100,0 \\
\hline \multicolumn{4}{|c|}{ Suplemento Mineral } \\
\hline Não & 22 & 16,4 & 17,7 \\
\hline Sim & 102 & 76,1 & 82,3 \\
\hline Sem dados & 10 & 7,5 & --- \\
\hline Total & 134 & 100,0 & 10,00 \\
\hline
\end{tabular}

${ }^{\mathrm{T}}$ Valor expresso em porcentagem, corrigido segundo o número de fazendas sem dados. ${ }^{2}$ Número de fazendas que não responderam.

Segundo SOUZA et al. (2007), a criação de pequenos ruminantes no Nordeste é historicamente praticada de forma extensiva, com nível rudimentar de tecnologia, pouca ou nenhuma assistência técnica, obtendo baixos índices de produtividade, resultando em uma baixa remuneração ao produtor. O manejo alimentar condiz com esse tipo de criação já que, como mostrado na Tabela 2, é baseado no pastejo em terras próprias $(99,1 \%$ dos casos) sendo relatado o descanso das pastagens em $57 \%$ das propriedades 
entrevistadas (69/121 propriedades, dado não tabulado). Uma alta porcentagem de produtores $(88,5 \%)$ relatou a suplementação alimentar com farelos de grãos, feno, bagaços etc., e mineral $(82,3 \%)$ com fósforo, cobre e cobalto. Essa suplementação compensaria as deficiências nutricionais da vegetação nativa da caatinga que apresenta uma acentuada redução anual na oferta de forragem durante as estações de seca (ARAÚJO et al., 2006).
Por outro lado, a análise dos dados mostra que na caprino/ovinocultura de tipo familiar os rebanhos criados pelas propriedades são de número pequeno, em sua maioria de 11 a 50 animais, sendo $43,5 \%$ rebanhos de caprinos e $56,6 \%$ de ovinos. $\mathrm{Na}$ Tabela 3, observam-se os resultados a respeito das características desses rebanhos. Eles são formados por animais sem raça definida (SRD) $(39,5 \%$ das propriedades) ou rebanhos mistos $(39,5 \%$ das propriedades), isto é, com animais SRD e de raça.

Tabela 3. Características dos rebanhos

\begin{tabular}{|c|c|c|c|}
\hline Variável & Número de Fazendas & Porcentagem & Validação $^{1}(\%)$ \\
\hline \multicolumn{4}{|l|}{ Composição do rebanho } \\
\hline SRD & 53 & 39,5 & 39,5 \\
\hline Misto (SRD e Raças) & 53 & 39,5 & 39,5 \\
\hline Raças & 28 & 21 & 21 \\
\hline Total & 134 & 100,00 & 100,00 \\
\hline \multicolumn{4}{|l|}{ Tipo de Criação } \\
\hline Caprinos & 13 & 9,7 & 9,8 \\
\hline Ovinos & 16 & 11,9 & 12,1 \\
\hline Caprinos e Ovinos & 17 & 12,7 & 12,9 \\
\hline Caprinos e bovinos & 9 & 6,7 & 6,8 \\
\hline Ovinos e bovinos & 20 & 14,9 & 15,2 \\
\hline Caprinos, Ovinos e Bovinos & 57 & 42,5 & 43,2 \\
\hline Sem dados ${ }^{2}$ & 2 & 1,5 & ---- \\
\hline Total & 134 & 100,00 & 100,00 \\
\hline \multicolumn{4}{|l|}{ Formas de Reprodução } \\
\hline Inseminação Artificial & 1 & 0,7 & 0,8 \\
\hline Monta controlada & 11 & 8,2 & 9,1 \\
\hline Transferência embrionária & 2 & 1,5 & 1,7 \\
\hline Monta natural & 107 & 79,9 & 88,4 \\
\hline Sem dados & 13 & 9,7 & --- \\
\hline Total & 134 & 100,0 & 100,0 \\
\hline \multicolumn{4}{|l|}{ Origem dos reprodutores } \\
\hline Comprados & 106 & 79,1 & 89,1 \\
\hline Cria & 1 & 0,7 & 0,8 \\
\hline Emprestados & 7 & 5,2 & 5,9 \\
\hline Trocas & 5 & 3,7 & 4,2 \\
\hline Sem dados & 15 & 11,2 & ---- \\
\hline Total & 134 & 100,0 & 100,0 \\
\hline \multicolumn{4}{|c|}{ Separação de animais jovens e adultos } \\
\hline Não & 98 & 73,1 & 81,0 \\
\hline Sim & 23 & 17,2 & 19,0 \\
\hline Sem dados & 13 & 9,7 & --- \\
\hline Total & 134 & 100,0 & 100,0 \\
\hline \multicolumn{4}{|c|}{ Exige documentos sanitários na compra do animal } \\
\hline Não & 107 & 79,9 & 84,3 \\
\hline Sim & 20 & 14,9 & 15,7 \\
\hline Sem dados & 7 & 5,2 & --- \\
\hline Total & 134 & 100,0 & 100,0 \\
\hline
\end{tabular}


O predomínio de animais SRD nos rebanhos está de acordo com o que foi descrito por PINHEIRO et al. (2000), que afirmam que grande parte do rebanho de caprinos e ovinos do Nordeste é composta por animais de raças nativas ou SRD. Nas outras propriedades, as raças encontradas foram predominantemente Boer, Anglo-Nubiano e Saanen em caprinos e Santa Inês e Dorper em ovinos. Essas raças tem um grande potencial para a produção de peles de boa qualidade para o mercado de calçados e vestuário (LEITE \& SIMPLICIO, 2002), porém isso não é explorado pelos produtores e seria uma alternativa comercial para o destino da produção. Além da criação de caprinos e/ou ovinos, detectou-se também a criação conjunta de bovinos, inclusive das três espécies juntas, em 65,2\% das propriedades. Segundo ARAUJO FILHO (2006), a criação conjunta de caprinos, ovinos e bovinos é comum no semiárido, mas pode contribuir com a diminuição da produtividade dos pequenos ruminantes, pois em períodos de escassez de alimento, os produtores dedicam os recursos primeiro aos bovinos, depois aos ovinos e por último aos caprinos.

Sobre o manejo reprodutivo nas propriedades, constatou-se que os reprodutores são obtidos por meio da compra em $89,1 \%$ das propriedades visitadas, obtidos por empréstimo em $5,9 \%$ ou por troca de animais $4,2 \%$. A exigência de documentos sanitários pelos produtores durante a compra de animais foi confirmada em apenas 15,7\% dos casos, inclusive, os animais comprados não são submetidos a quarentenários, na maioria das vezes (96\%; 116/121 propriedades, dados não tabulados). Na Tabela 3 também se observa que a monta natural é a forma mais comum de reprodução em $88,4 \%$ dos casos, sem nenhuma época definida de estação de monta. Também foi constatado o baixo nível tecnológico utilizado na reprodução já que apenas em alguns rebanhos foi relatado o uso de técnicas reprodutivas como inseminação artificial $(0,8 \%)$ ou transferência de embriões $(1,7 \%)$. Esses resultados são similares aos de outros trabalhos realizados na região de Juazeiro-BA (SOUZA et al., 2007), que detectaram a prática da monta natural em torno de $90 \%$ das propriedades pesquisadas. Nesse perfil, os cruzamentos entre os animais ocorrem em condições inadequadas de idade, peso, ciclo andrológico, período de cio das fêmeas, assim como a relação macho/fêmea. As características das crias da monta natural (dados não tabulados) mostraram que são alimentadas por meio do aleitamento natural $(95,7$; $112 / 117$ propriedades) com desmame até os 2 meses de vida $(50,7 \% ; 66 / 130$ propriedades). Esse sistema reprodutivo pouco desenvolvido também se manifesta quando não separa animais jovens e adultos (Tabela 3) (81\%; 98/134 propriedades), ficando os animais jovens precocemente expostos a infecções decorrentes do contato com os adultos.

Na Tabela 4, observa-se o perfil e o destino da produção desses rebanhos. A finalidade das criações é principalmente para a produção de carne (57,6\% dos casos) ou de carne e leite $(39,4 \%$ das propriedades). A renda dessas propriedades vem da venda de carne em 59,6\% dos casos, sendo que essa produção também se destina ao consumo pelos próprios produtores em $78,3 \%$ dos casos.

$\mathrm{O}$ excedente destina-se principalmente ao próprio município $(82,9 \%)$, mas a falta de inserção do caprino/ovinocultor na rede de comercialização/integração dos mercados faz com que, em apenas $5,4 \%$ dos casos, o produto excedente seja destinado a frigoríficos, sendo que os principais compradores são os intermediários ou atravessadores $(60,9 \%)$ e o próprio mercado local $(26,4 \%)$.

Essa venda é realizada com animais em pé (vivos) em 90,6\% das propriedades. Os estudos de PAMPONET (2009) mostram que a caprinocultura é uma atividade importante porque garante a produção de alimentos e, igualmente, a geração de renda para as famílias rurais do semiárido baiano. Os dados da comercialização aqui apresentados revelam um subaproveitamento da produção, observando-se a baixa diversificação dos produtos. Como alternativas, pode-se citar a venda de couro, cujos preços nos mercados são atrativos, e de outros produtos com mais alto valor agregado, tais como embutidos, defumados e carnes com cortes padronizados, além de leite e seus derivados. Dessa forma, a comercialização rudimentar contribui para a não inserção da caprino/ovinocultura em mercados mais rentáveis.

Com relação às práticas de manejo sanitário (Tabela 5), a pesquisa mostrou resultados variáveis porque muitas propriedades não responderam o questionário completamente. Dentre as práticas sanitárias mais comuns, a vermifugação $(91,3 \%)$ e as vacinações (raiva, clostridioses: $51,3 \%$ das propriedades) foram as mais difundidas. A realização de exames foi observada em apenas $15,8 \%$ das propriedades.

Observa-se uma ausência de implantação de práticas e/ou instalações (presença de esterqueiras) que proporcionem a priorização da prevenção de doenças, ao invés de ações curativas. Entre as doenças mais citadas pelos produtores, destacaramse aquelas de habitual ocorrência nos rebanhos do semiárido (OLIVEIRA \& ALBUQUERQUE, 2008), como linfadenite caseosa $(71,9 \%)$, ectima contagioso (55\%) e ectoparasitoses (47,2\%). Em nenhuma propriedade foi citada a ocorrência de SRLV por parte dos produtores. Isso condiz com a baixa soroprevalência de SRLV encontrada nas 
propriedades estudadas. Podem-se relacionar três aspectos do perfil da caprino/ovinocultura da região que validam os resultados desta pesquisa. A entrada/disseminação do vírus estaria limitada: pelo sistema de criação extensivo (com animais criados livres e com pouco contato entre eles), pela baixa introdução de animais de raça nos rebanhos e pela exploração para produção de carne, em contraponto à maior ocorrência do SRLV em propriedades com maior nível de tecnificação, criações de sistema intensivo, com animais de raça e exploração para produção de leite (SILVA et al., 2005), elementos que contribuem para a disseminação do vírus no rebanho. Contudo, o que se observa é que as mesmas características que funcionam como uma barreira para a entrada/disseminação do vírus nas propriedades estudadas também estão associadas a um perfil de pouca tecnificação, fortemente presente no semiárido baiano. Esse perfil tem como principais aspectos o manejo ineficiente, a nutrição precária, problemas sanitários, baixo potencial genético dos animais e baixa adoção de tecnologias, o que torna a caprino/ovinocultura uma produção voltada para a subsistência dos próprios criadores e/ou para o comércio local.

Tabela 4. Perfil e destino da produção das propriedades estudadas

\begin{tabular}{|c|c|c|c|}
\hline Variável & Número de Fazendas & Porcentagem & Validação $^{1}(\%)$ \\
\hline \multicolumn{4}{|l|}{ Tipos de Exploração } \\
\hline Corte & 76 & 56,7 & 57,6 \\
\hline Leite & 4 & 3,0 & 3,0 \\
\hline Mista & 52 & 38,8 & 39,4 \\
\hline Sem Dados ${ }^{2}$ & 2 & 1,5 & --- \\
\hline Total & 134 & 100,0 & 100,0 \\
\hline \multicolumn{4}{|l|}{ Renda da caprino/ovinocultura } \\
\hline Carne & 53 & 39,6 & 59,6 \\
\hline Carne e Leite & 4 & 3,0 & 4,5 \\
\hline Carne e pele & 24 & 17,9 & 27,0 \\
\hline Carne, Pele e Leite & 7 & 5,2 & 7,9 \\
\hline Leite & 1 &, 7 & 1,1 \\
\hline Total & 134 & 100,00 & 100,00 \\
\hline \multicolumn{4}{|l|}{ Locais de Venda dos Produtos } \\
\hline Em outras cidades & 4 & 3,0 & 3,4 \\
\hline Em outros estados & 1 & 0,7 & 0,9 \\
\hline No próprio município & 97 & 72,4 & 82,9 \\
\hline $\begin{array}{l}\text { No próprio município e em } \\
\text { outras cidades }\end{array}$ & 15 & 11,2 & 12,8 \\
\hline Sem Dados & 17 & 12,7 & --- \\
\hline Total & 134 & 100,0 & 100,0 \\
\hline \multicolumn{4}{|l|}{ Destino da produção } \\
\hline Frigorifico & 4 & 3,0 & 3,6 \\
\hline $\begin{array}{l}\text { Frigorifico e Intermediário e } \\
\text { Mercado Local }\end{array}$ & 2 & 1,4 & 1,8 \\
\hline Intermediário & 67 & 50,0 & 60,9 \\
\hline $\begin{array}{l}\text { Intermediário e Mercado } \\
\text { Local }\end{array}$ & 8 & 6,0 & 7,3 \\
\hline Mercado Local & 29 & 21,6 & 26,4 \\
\hline Sem Dados & 24 & 17,9 & ---- \\
\hline Total & 134 & 100,0 & 100,0 \\
\hline \multicolumn{4}{|c|}{ Utilização da carne para o consumo familiar } \\
\hline Não & 25 & 18,7 & 21,7 \\
\hline Sim & 90 & 67,2 & 78,3 \\
\hline Sem Dados & 19 & 14,2 & ---- \\
\hline Total & 134 & 100,0 & 100,0 \\
\hline
\end{tabular}


Tabela 5. Práticas sanitárias e enfermidades relatadas nas propriedades entrevistadas

\begin{tabular}{|c|c|c|c|}
\hline Variável & Número de Fazendas & Porcentagem & Validação $^{1}(\%)$ \\
\hline \multicolumn{4}{|c|}{ Vermifugação } \\
\hline Não & 10 & 7,5 & 8,3 \\
\hline Sim & 110 & 82,1 & 91,7 \\
\hline Sem Dados ${ }^{2}$ & 14 & 10,4 & ---- \\
\hline Total & 134 & 100,0 & 100,0 \\
\hline \multicolumn{4}{|c|}{ Vacinação do rebanho } \\
\hline Não & 57 & 42,5 & 48,7 \\
\hline $\operatorname{Sim}$ & 60 & 44,8 & 51,3 \\
\hline Sem Dados & 17 & 12,7 & --- \\
\hline Total & 134 & 100,0 & 100,0 \\
\hline \multicolumn{4}{|c|}{ Presença de Esterqueira } \\
\hline Não & 99 & 73,9 & 81,8 \\
\hline Sim & 22 & 16,4 & 18,2 \\
\hline Sem dados & 13 & 9,7 & --- \\
\hline Total & 134 & 100,0 & 100,0 \\
\hline \multicolumn{4}{|c|}{ Realiza exames laboratoriais } \\
\hline Não & 101 & 75,4 & 84,2 \\
\hline $\operatorname{Sim}$ & 19 & 14,2 & 15,8 \\
\hline Sem Dados & 14 & 10,4 & ---- \\
\hline Total & 134 & 100,0 & 100,0 \\
\hline \multicolumn{4}{|c|}{ Linfadenite caseosa (Mal do caroço) } \\
\hline Não & 34 & 25,4 & 28,1 \\
\hline Sim & 87 & 64,9 & 71,9 \\
\hline Sem dados & 13 & 9,7 & --- \\
\hline Total & 134 & 100,0 & 100,0 \\
\hline \multicolumn{4}{|c|}{ Ectoparasitas (piolhos,carrapatos) } \\
\hline Não & 63 & 47,0 & 52,5 \\
\hline $\operatorname{Sim}$ & 57 & 42,5 & 47,5 \\
\hline Sem Dados & 14 & 10,4 & --- \\
\hline Total & 134 & 100,0 & 100,0 \\
\hline \multicolumn{4}{|c|}{ Pododermatite (Mal do casco) } \\
\hline Não & 96 & 71,6 & 80,7 \\
\hline Sim & 23 & 17,2 & 19,3 \\
\hline Sem Dados & 15 & 11,2 & --- \\
\hline Total & 134 & 100,0 & 100,0 \\
\hline \multicolumn{4}{|c|}{ Ectima contagioso (Boqueira) } \\
\hline Não & 66 & 49,3 & 55,0 \\
\hline Sim & 54 & 40,3 & 45,0 \\
\hline Sem Dados & 14 & 10,4 & --- \\
\hline Total & 134 & 100,0 & 100,0 \\
\hline \multicolumn{4}{|c|}{ Quadros Diarreicos } \\
\hline Não & 49 & 36,6 & 40,5 \\
\hline Sim & 72 & 53,7 & 59,5 \\
\hline Sem Dados & 13 & 9,7 & --- \\
\hline Total & 134 & 100,00 & 100,0 \\
\hline
\end{tabular}

${ }^{1}$ Valor expresso em porcentagem, corrigido segundo o número de fazendas sem dados.

2 Número de fazendas que não responderam. 


\section{CONCLUSÕES}

A caprino/ovinocultura nas regiões estudadas apresentou um perfil de baixa tecnificação, voltado para a subsistência dos produtores, com modos rudimentares de comercialização, o que dificulta a sua inserção em mercados de maior rentabilidade.

A baixa ocorrência de infecção por SRLV nas propriedades estudadas relaciona-se com o perfil encontrado, pois os animais são criados em sistemas extensivos, sem entrada de animais de raça, aliado à baixa permanência do animal no rebanho para o próprio consumo ou venda da carne.

\section{AGRADECIMENTOS}

Fundação de amparo à pesquisa do estado da Bahia (FAPESB) pelo apoio financeiro Edital Semiárido- 0005/2007. A equipe de técnicos e veterinários do setor de caprinos e ovinos da $\mathrm{ADAB}$ que direta ou indiretamente colaboraram no trabalho.

\section{REFERÊNCIAS}

ALMEIDA, M.G.A.R.; ANUNCIAÇÃO, A.V. M.; FIGUEIREDO, A. MARTINEZ, T. C.N.; LABORDA, S.S. Dados sorológicos sobre a presença e distribuição da artriteencefalite caprina (CAE) no Estado da Bahia, Brasil. Revista Brasileira de Saúde Produção Animal, v.1, n.3, p.78-83, 2001.

ARAUJO FILHO, J.A. Aspectos zooecológicos e Agropecuários do Caprino e do Ovino nas regiôes semiáridas Embrapa Caprinos, 2006. 28p (Embrapa Caprinos. Documentos, 61). Disponível em: http://www.cnpc.embrapa.br/doc/7166396/doc61-Embrapa Acesso em Dez 2010.

FRANKE, C.R. Controle Sanitário da Artrite-Encefalite Caprina. Salvador, Ed. EDUFBA 1998. 71p.

GOFF, S.P. Retroviridae: The retroviruses and their replication. In: Fields Virology. 2 ed., 2006, p 1999-2069.

IBGE. Pesquisa da Pecuária Municipal - Disponível em:<http://www.sidra.ibge.gov.br>. 2005. Acesso em 18 dez.2010

LEITE, E.R.; SIMPLÍCIO, A.A. Produção mercado das peles caprina e ovina. Sobral: Embrapa Caprinos e Ovinos, 2002. 27p.

LIMA, R.G.S.; BAIARDI, A. Estratégias de sobrevivência dos pequenos caprinocultores do semiárido baiano. 2002 Disponível

<http://www.66.102.1.104/scholar?hl=ptR\&lr=\&q=cache:bE N9qllYJ:gipaf.cnptia.embrapa.br/itens/publ/sober2000/limar gs/Paper1593.PDF++importancia+cultural+do+caprino>
Acesso em 12 dez 2010.

MCNEILLY, T.N.; BAKER, A.; BROWN, J.K.; COLLIE, D; MACLACHLAN, G.; RHIND, S.M; HARKISS, G. Role of Alveolar Macrophages in Respiratory Transmission of Visna/MaediVirus. Journal of Virology, v.82, n.3, p.15261536, 2008.

OLIVEIRA, E.L.; ALBUQUERQUE, M.A.R.F.H. Manejo Sanitário de Pequenos Ruminantes, Documentos Online EMBRAPA. 2008.2 Disponível em: http://www.cnpc.embrapa.br/admin/pdf/03155000120122.do c77.pdf, acesso em 30 out. 2012.

OLIVEIRA, M.M.M.; MELO, M.A.; ANDRADE, P. P. de; GOMES, S. M.; CAMPOS, A.C.; NASCIMENTO, S.A.; CASTRO, R.S. Western blot para o diagnóstico das infecções pelos lentivírus de pequenos ruminantes em caprinos: um método simples para produção de antígeno. Arquivos do Instituto Biologico, v.75, n.3, p.263-270, 2008.

PAMPONET, A.S. Do autoconsumo ao mercado: os desafios atuais para a caprinocultura no nordeste semiárido da Bahia. Revista Desenbahia, n.10, p.123-144, 2009.

PINHEIRO, R.R; GOUVEIA, A.M.G; ALVES, F.S. F; HADDAD, J.P.A. Aspectos epidemiológicos da caprinocultura cearense. Arquivo Brasileiro de Medicina Veterinária e Zootecnia, v.52, n.5, p.534-43, 2000.

SEAGRI, Secretaria de agricultura, irrigação e reforma agraria. Bahia territórios de identidade Disponível em $<$ http://www.seagri.ba.gov.br/bahia_territorios_identidade.as p>. Acesso em 10 out 2012.

SILVA, J.S.; CASTRO, R.S.; MELO, C.B.; FEIJÓ, F.M.C. Infecção pelo vírus da artrite encefalite caprina no Rio Grande do Norte. Arquivo Brasileiro de Medicina Veterinária e Zootecnia, v.57, n.6, p.726-731, 2005.

SOUZA, T.S.; COSTA, J.N.; MARTINEZ, P. M.; PINHEIRO, R. R. Estudo sorológico da Maedi-Visna pelo método da imunodifusão em gel de ágar em rebanhos ovinos de Juazeiro, Bahia, Brasil. Revista Brasileira de Saúde e Produção Animal, v.8, n.4, p. 276-282, 2007.

SYNGE, B.A.; RITCHIE, C.M. Elimination of small ruminant lentivirus infection from sheep flocks and goat herds aided by health schemes in Great Britain. Veterinary Record, v.167, p.739-743, 2010.

Tigre DM, Campos GS, Sardi S.I. Isolamento do vírus da Artrite-encefalite caprina a partir do co-cultivo de células mononucleares do sangue com células de membrana sinovial de cabras. Revista de Ciências Medicas e Biológicas, v.5, p100-108, 2006.

TORRES JA, CAMPOS GS, FREITAS MM, BRANDÃO CFL, SARDI S.I Produção de antígeno viral para o sorodiagnóstico da Artrite encefalite caprina utilizando um teste imunoenzimatico (ELISA). Revista de Ciências Medicas e Biológicas v.8, p.107- 114, 2009. 